\title{
Identification of the Prevailing Antigenic Types of Canine Parvovirus in Northern and Central India
}

\author{
Sankalp Singh Kushwaha, Gurpreet Kaur*, Mudit Chandra and P.N. Dwivedi \\ Department of Veterinary Microbiology, COVS, Guru Angad Dev Veterinary and Animal \\ Sciences University, Ludhiana-141001, Punjab, India \\ *Corresponding author
}

\section{A B S T R A C T}

\section{Keywords}

Canine Parvovirus, dogs, Antigenic types, PCR, Nested PCR, Real Time PCR

Article Info

Accepted:

20 July 2018

Available Online:

10 August 2018
CPV-2 causes hemorrhagic gastroenteritis in dogs and spreads rapidly in both domestic as well as wild population of canines. The virus sheds in large numbers in the feces, so the present study was designed to detect CPV and to identify the prevailing antigenic types of CPV using molecular techniques from rectal swabs of affected dogs. The incidence of CPV was found to be $18 \%$ and $63 \%$ by PCR and NPCR respectively. The most prevailing antigenic type as detected by Real time PCR was found to be CPV-2a. Further the study also indicated the animals vaccinated for CPV were also found positive for the disease.

\section{Introduction}

Canine parvovirus (CPV) is a single stranded DNA non-enveloped icosahedral virus with approximate diameter of $20 \mathrm{~nm}$ belonging to the genus Parvovirus under the family Parvoviridae (Tijssen et al., 1999). The phylogenetic analysis reveals that CPV originated from feline panleukopenia virus or a very closely related carnivore parvovirus of feral canids like foxes and mink (Mochizuki et al., 2008). CPV-2 causes hemorrhagic gastroenteritis in dogs and spreads rapidly in both domestic as well as wild population of canines. The virus has affinity for villi of the small intestine where they replicate in the rapidly dividing epithelial cells. The virus sheds in large numbers in the feces for four to seven days post infection (Hoelzer et al., 2008) and thus, feces are known to serve as a source of infection. Therefore, feces constitutes as the most suitable material for detection of CPV (Carmichael and Binn, 1981).

CPV strains have undergone a series of evolutionary selections in nature, resulting in global distribution of new variants that have replaced the original CPV-2. Currently, the three major antigenic variants of CPV-2 which are known to be distributed among the dog population worldwide are i.e. $2 \mathrm{a}, 2 \mathrm{~b}$ and $2 \mathrm{c}$ (Decaro et al., 2006). Isolation of CPV-2 was 
done for the first time in India by Ramadass and Khader in 1982 since then several occurrence of disease have been reported from different parts of the country involving different variants of $\mathrm{CPV}(2,2 \mathrm{a}, 2 \mathrm{~b}$ and $2 \mathrm{c})$ both in vaccinated and unvaccinated animals (Deepa and Saseendrannath, 2000; Phukan et al., 2004; Biswas et al., 2006). VP2 is the major capsid protein that plays an important role in the determination of antigenicity and host range of CPV.

It is also known that the mutations which affect VP2 gene are mainly responsible for evolving different antigenic variants of CPV (Phromnoi et al., 2010). The early detection along with the knowledge of genetic variations of VP2 can be of immense help in identifying the emerging CPV strains. Thus the present study was designed to detect CPV and identify the prevailing antigenic types of $\mathrm{CPV}$ in the region under study using molecular techniques.

\section{Materials and Methods}

A total of 100 rectal swabs were collected in phosphate buffer saline $(\mathrm{pH}=7.2)$ from dogs exhibiting clinical signs of gastroenteritis, hemorrhagic enteritis, pyrexia etc. Samples were collected from Madhya Pradesh $(n=11)$ [TVCC, Jabalpur (n=7); Govt. veterinary hospital, Bhopal $(n=4)]$ and Ludhiana, Punjab $(n=89)$ [the small animal veterinary clinics, Guru Angad Dev Veterinary and Animal Sciences University]. The samples were collected from February 2017 to June 2018. All the rectal swabs were kept at $4{ }^{\circ} \mathrm{C}$ till further use. The vaccine Nobivac DHPPi (Intervet, Pvt. Ltd) was procured commercially from local market. The DNA was extracted from all the samples and the vaccine using the phenol-chloroform extraction method as described by Sambrook and Russell, 2001.

Polymerase Chain Reaction (PCR) for the

\section{detection of canine parvovirus}

The primers used in PCR were as per Mizak and Rzezutka (1999). The PCR reaction was set up by adding, 5.0 $\mu$ l of 10X PCR buffer (with $15 \mathrm{mM} \mathrm{MgCl}$ ), $1.0 \mu$ l of forward and reverse primer $(20 \mathrm{pm} / \mu \mathrm{l})$ each, $1.0 \mu \mathrm{l}$ of dNTPs mix (10 mM each), 1 U Taq DNA polymerase, $15 \mu \mathrm{l}$ of the template DNA and the reaction was made up to $50 \mu 1$ using nuclease free water. The rectal swab from a healthy dog was used as a negative control and a DNA from a vaccine (DHPPI) was used as a positive control.

\section{Nested PCR (NPCR) for the detection of Canine Parvovirus}

The primers used for NPCR were as per Mizak and Rzezutka (1999). NPCR reaction was set up by adding $5 \mu 1$ of the PCR product (from above reaction), $2.5 \mu \mathrm{l}$ of $10 \mathrm{X}$ PCR buffer (with $15 \mathrm{mM} \mathrm{MgCl}_{2}$ ), $1.0 \mu \mathrm{l}$ each of forward and reverse primer $(20 \mathrm{pm} / \mu \mathrm{l}), 1.0 \mu \mathrm{l}$ of dNTPs (10 mM each), 1 U Taq DNA polymerase and the final volume was made up to $25 \mu 1$ by adding nuclease free water.

The rectal swab from a healthy dog was used as a negative control and a DNA from a vaccine was used as a positive control.

In both PCR and nested PCR, the reaction was put in a thermocycler (Veriti ${ }^{\circledR}$, Life Technologies, USA) with 35 cycles of denaturation at $94^{\circ} \mathrm{C}$ for $60 \mathrm{~s}$, annealing at $55^{\circ} \mathrm{C}$ for 60 s, elongation at $72^{\circ} \mathrm{C}$ for 150 s and a final elongation at $72^{\circ} \mathrm{C}$ for $10 \mathrm{~min}$.

PCR and Nested PCR products $(10 \mu \mathrm{l})$ were run using $1.5 \%$ agarose at 5 volts $/ \mathrm{cm}$ with Gene Ruler ladder plus 100bp (New England Biolabs, USA). The gel was visualized and photographed using Gel documentation system (AlphaImager, USA).

Real-Time PCR for antigenic typing of 


\section{CPV}

The samples which were positive for CPV by Nested PCR were subjected to Real Time PCR for antigenic typing of CPV for three antigenic type's viz. CPV-2, CPV-2a and CPV-2b. The fluorescence-probe based assays (Taqman assays) for the three antigenic types viz CPV2, CPV-2a and CPV-2b (Table 1) were used. The primers and probe for the three antigenic types were got custom synthesized (IDT).

For the Real-Time PCR $2 \mu 1$ of the template DNA was added to the reaction mixture consisting of $10 \mu \mathrm{l}$ of $2 \mathrm{X}$ Taqman ${ }^{\circledR}$ Universal Master Mix II with UNG (Applied Biosystems), $1.0 \mu \mathrm{l}$ of $20 \mathrm{X}$ Taqman $^{\circledR}$ assay (for the individual antigenic type) and the final volume $20 \mu 1$ was made by adding nuclease free water. The PCR reaction was carried out in $\mathrm{CFX}^{\mathrm{TM}} 96$ Real-Time System (BioRad, USA) with the thermal conditions of UNG incubation at $50^{\circ} \mathrm{C}$ for 2 minutes, polymerase activation at $95^{\circ} \mathrm{C}$ for 3 minutes and 40 cycles of denaturation at $95^{\circ} \mathrm{C}$ for 15 seconds and annealing at variable temperatures and time depending upon the antigenic type detected. For detection of CPV-2 the annealing was done at $52^{\circ} \mathrm{C}$ for 30 seconds; for CPV-2a the annealing was done at $61{ }^{\circ} \mathrm{C}$ for 45 seconds and for CPV-2b annealing was carried out at $57^{\circ} \mathrm{C}$ for 45 seconds. The samples which were negative for both CPV-2 and CPV-2a were subjected to detection for CPV-2b in RealTime PCR. The DNA from vaccine (DHPPi) was used as positive control and nuclease free water was used as negative control.

\section{Determination of end point}

The samples were considered positive or negative in the Real-Time PCR depending upon the fluorescence of a particular wavelength emitted by the respective fluorophore attached to the particular probe for the three antigenic types (CPV-2, CPV-2a and $\mathrm{CPV}-2 \mathrm{~b}$ ) of CPV. Depending upon the highest and lowest relative fluorescence unit (RFU) value, the cut off value or end point was calculated by using CFX Manager Version 3.1.

\section{Sequence analysis}

The PCR products of two samples [one from Ludhiana (L50) and one from Madhya Pradesh (M1)] were got sequenced from Eurofins Genomics India Pvt. Ltd and were analysed and compared with the available CPV sequences in the gene bank using NCBI BLAST.

\section{Results and Discussion}

Polymerase Chain Reaction (PCR) and Nested PCR (NPCR) for the detection of CPV

In the present study, a total of one hundred $(n=100)$ rectal swabs were collected from the dogs exhibiting signs of diarrhoea, gastroenteritis and haemorrhagic enteritis with pyrexia. The genomic DNA was extracted from these samples and subjected to PCR revealed that out of a total of hundred samples 18 samples were found positive by PCR yielding a product size of 1198 bp (Figure 1). Thus, in the present study the incidence of CPV was found to be $18 \%$ using PCR. Out of these 18 positive samples seven dogs had the history of vaccination for CPV.

The PCR products from the 100 rectal swabs were subjected to NPCR. Out of these 100 samples, 63 samples were positive with nested PCR yielding a product size of 548bp (Figure 2) indicating that the incidence of CPV with NPCR to be $63 \%$. Out of these 63 positive samples, 6 samples (6/11) were from Madhya Pradesh and 57 samples (57/89) from Ludhiana, Punjab. Out of the 63 positive samples, 30 dogs had the history of being 
vaccinated for Canine Parvovirus. Out of these 30 vaccinated dogs positive for CPV, three were from Madhya Pradesh and 27 from Ludhiana, Punjab.

Many workers have used PCR and NPCR for detection of CPV in rectal swabs/feces of dogs (Mochizuki et al., 1993, Schunck et al., 1995, Weiquan et al., 2001) and have reported it to be specific, sensitive and simple method for detection of canine parvovirus in faeces of infected dogs. In India, Parthiban et al., (2010) from Pondicherry reported $53.12 \%$ dogs as positive for CPV using PCR from a total of 128 faecal samples/rectal swabs. Kumar and Nandi (2010b) analyzed 129 faecal samples and found 78 were positive for canine parvovirus by PCR. In another study Singh et al., (2013) screened 100 faecal samples from dogs with signs of gastroenteritis and found 63 dogs were positive for CPV. Also Kaur et al., (2015) screened 100 samples from dogs suspected of CPV and found 11 samples to be positive for CPV by PCR.

From the study it was revealed that the sensitivity of NPCR was much more than PCR for detecting CPV. Similar findings indicating increased sensitivity of NPCR has been reported by various earlier workers. The results are similar to Hirasawa et al., (1994), Sakulwira et al., (2001) and Schmitz et al., (2009) who have also stated that nested PCR being more sensitive than conventional PCR. The reason for this could be that the samples containing very few virus particles might be harbouring inhibitory substances as reported by Kumar et al., (2011) leading to absence of visualization of the amplified product after a PCR which could have been resolved using a NPCR leading to visualization of NPCR product in an agarose gel. Mizak and Rzezutka (1999) used nested PCR for detection of canine parvovirus in faeces by targeting VP2 gene of $\mathrm{CPV}$ and reported that the sensitivity of detection of CPV in 10 stool samples by nested PCR was increased 60 per cent in comparison with the standard PCR method. In an another study conducted by Kaur et al., (2011), when 65 samples from dogs subjected to PCR and NPCR yielded $3(4.61 \%)$ and 21 $(57.24 \%)$ positive reaction respectively. In a study conducted by Kaur et al., (2015) demonstrated more number of samples positive by NPCR (50/100) as compared to PCR (11/100).

\section{Real-Time PCR to detect antigenic types of canine parvovirus}

The DNA from the samples positive for CPV by NPCR $(n=63)$ were screened individually for three different fluorescence probe-based Real-Time PCR assay viz. CPV-2, CPV-2a and CPV-2b.

Among the positive samples, 10 (10/63, $15.87 \%$ ) animals were positive for CPV-2 and 39 (39/63, 61.90\%) were positive for CPV-2a (Table 2). The samples which were negative for CPV-2 and CPV-2a were screened for CPV-2b and no amplification was observed for CPV-2b. Thus, from the study it was found that the most prevailing antigenic type in dog population was CPV-2a. When we examined for the presence of more than one antigenic type in a sample, it was found that nine animals were positive for both CPV-2 and CPV-2a.

Out of the ten samples positive for CPV-2, five animals had history of vaccination for CPV and out of the 39 samples positive for CPV-2a, 16 animals had the history of vaccination for $\mathrm{CPV}$.

VP2, a capsid protein, is the main immunodominant protein of CPV. It is important for the determination of antigenic types based on the epitopes located on the VP2 protein region. 
Fig.1 PCR for detection of canine parvovirus

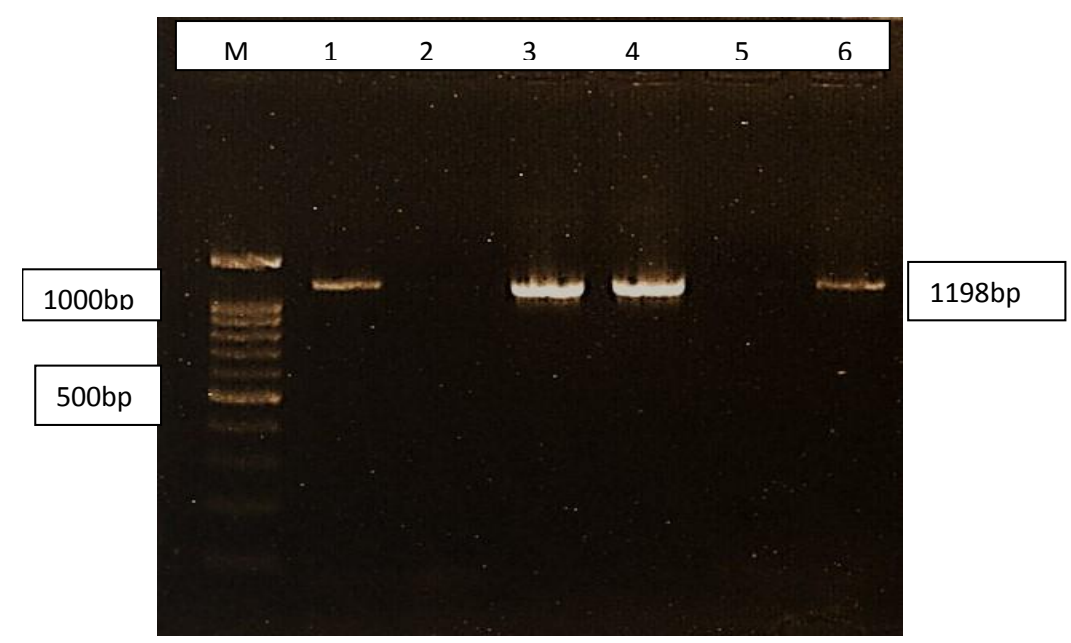

Lane M: DNA ladder 100bp plus, Lane 1, 3, 6: positive samples for CPV, Lane 2: negative samples for CPV, Lane 4: Positive control, Lane 5: Negative control

Fig.2 Nested PCR for detection of canine parvovirus

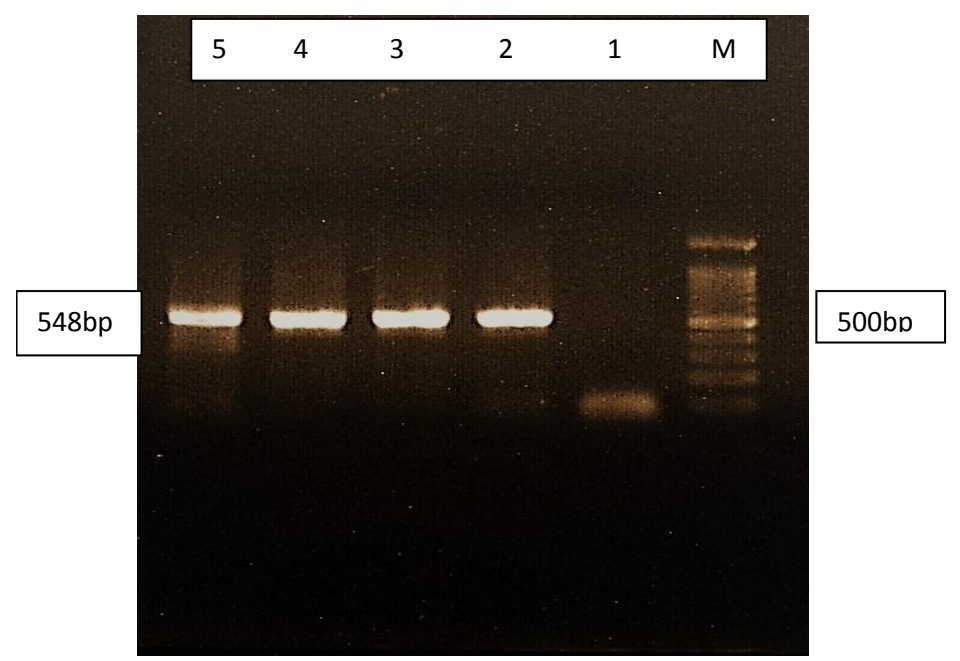

Lane M: DNA ladder 100bp plus, Lane 1: Negative control, Lane 2: Positive control, Lane 3, 4, 5: positive samples for CPV

Table.1 Taqman assays for the three antigenic types of CPV

\begin{tabular}{|c|c|c|c|c|c|c|}
\hline S. No. & $\begin{array}{c}\text { Antigenic } \\
\text { Type }\end{array}$ & $\begin{array}{l}\text { Taqma } \\
\text { n Assay }\end{array}$ & Sequence & Reference & $\begin{array}{l}\text { Position in } \\
\text { genome }\end{array}$ & $\begin{array}{c}\text { Annealing } \\
\text { temperature }\left({ }^{\circ} \mathrm{C}\right)\end{array}$ \\
\hline \multirow{3}{*}{1.} & \multirow{3}{*}{ CPV-2 } & $\mathrm{F}$ & 5'-AAACAGGAATTAACTATACTAATATATTTA-3' & \multirow{3}{*}{$\begin{array}{l}\text { Decaro et } \\
\text { al., } 2005\end{array}$} & - & \multirow{3}{*}{52} \\
\hline & & $\mathrm{R}$ & 5'-AAATTTGACCATTTGGATAAACT-3' & & - & \\
\hline & & Probe & 5'-/6-FAM/TGGTCCTTT/ZEN/AACTGCATTAAATAATGTACC/IowaBlack/3' & & - & \\
\hline \multirow{3}{*}{2.} & \multirow{3}{*}{ CPV-2a } & $\mathrm{F}$ & 5'-TGACCAAGGAGAACCAACTAAC -3' & \multirow{3}{*}{$\begin{array}{l}\text { Decaro et } \\
\text { al., } 2006\end{array}$} & $847-866$ & \multirow{3}{*}{61} \\
\hline & & $\mathrm{R}$ & 5'-TGATCTGCTGGCGAGAAATATAA-3' & & $1013-993$ & \\
\hline & & Probe & 5'/6-FAM/ACGCTGCTT/ZEN/ATCTTCGCTCTGGT/IowaBlack/-3' & & $867-896$ & \\
\hline \multirow{3}{*}{3.} & \multirow{3}{*}{ CPV-2b } & $\mathrm{F}$ & 5'-ACAGGAAGATATCCAGAAGGAGA-3' & \multirow{3}{*}{$\begin{array}{c}\text { Kaur } e t \\
\text { al., } 2016\end{array}$} & $1216-1238$ & \multirow{3}{*}{57} \\
\hline & & $\mathrm{R}$ & 5'-TGACCATTTGGATAAACTGGTGG-3' & & $1403-1381$ & \\
\hline & & Probe & 5'-/HEX/TATTAACTT/ZEN/TAACCTTCCTGTAACAGATGA-/Iowa Black/-3' & & $1251-1280$ & \\
\hline
\end{tabular}


Table.2 Description (Age, Sex, Breed and Vaccination Status) of samples positive by Real-Time PCR

\begin{tabular}{|c|c|c|c|c|c|c|c|c|}
\hline \multirow[t]{2}{*}{ S. No. } & \multirow[t]{2}{*}{ Sample } & \multirow{2}{*}{$\begin{array}{l}\text { Age } \\
\text { (months) }\end{array}$} & \multirow[t]{2}{*}{ Sex } & \multirow[t]{2}{*}{ Breed } & \multirow{2}{*}{$\begin{array}{l}\text { Vaccinatio } \\
\text { n status }\end{array}$} & \multicolumn{3}{|c|}{ Real Time PCR } \\
\hline & & & & & & CPV-2 & CPV-2a & CPV-2b \\
\hline 1. & M1 & 11 & M & ND & + & + & + & - \\
\hline 2. & M3 & 1 & $\mathrm{~F}$ & Rottweiler & - & - & + & - \\
\hline 3. & M5 & 6 & M & GSD & + & + & + & - \\
\hline 4. & L25 & 5 & $\mathrm{~F}$ & Golden Retreiver & + & - & + & - \\
\hline 5. & L27 & 3 & $\mathrm{~F}$ & ND & + & - & + & - \\
\hline 6. & L28 & 5 & M & ND & - & - & + & - \\
\hline 7. & L30 & 2 & $\mathrm{~F}$ & Beaglehound & + & - & + & - \\
\hline 8. & L34 & 2 & M & Pitbull & - & - & + & - \\
\hline 9. & L43 & 5 & $\mathrm{~F}$ & American bullie & + & - & + & - \\
\hline 10. & L45 & 5 & $\mathrm{~F}$ & ND & - & - & + & - \\
\hline 11. & L46 & 1.5 & M & GSD & - & - & + & - \\
\hline 12. & L50 & 7 & $\mathrm{~F}$ & Rottweiler & + & - & + & - \\
\hline 13. & L5 1 & 4 & $\mathrm{~F}$ & ND & + & + & + & - \\
\hline 14. & L52 & 4 & M & Rottweiler & + & + & + & - \\
\hline 15. & L53 & 2 & M & ND & - & - & + & - \\
\hline 16. & L54 & 6 & $\mathrm{~F}$ & Pug & - & - & + & - \\
\hline 17. & L57 & 1 & M & Beaglehound & - & - & + & - \\
\hline 18. & L60 & 1.5 & $\mathrm{~F}$ & Cocker Spaniel & + & - & + & - \\
\hline 19. & L61 & 3 & $\mathrm{~F}$ & Boxer & - & - & + & - \\
\hline 20. & L63 & 3 & M & ND & - & + & + & - \\
\hline 21. & L64 & 5 & M & ND & - & - & + & - \\
\hline 22. & L65 & 1.5 & M & GSD & + & - & + & - \\
\hline 23. & L69 & 3 & $\mathrm{~F}$ & Pitbull & + & - & + & - \\
\hline 24. & L70 & 2.5 & $\mathrm{~F}$ & Bully & + & + & + & - \\
\hline 25. & L72 & 2.5 & $\mathrm{~F}$ & GSD & - & + & + & - \\
\hline 26. & L73 & 3 & M & ND & - & - & + & - \\
\hline 27. & L76 & 1.5 & $\mathrm{~F}$ & PakistanBully & - & - & + & - \\
\hline 28. & L77 & 1 & $\mathrm{~F}$ & Labrador & - & - & + & - \\
\hline 29. & L78 & 1.5 & $\mathrm{~F}$ & Dachshund & - & - & + & - \\
\hline 30. & L79 & 2 & $\mathrm{~F}$ & Dachshund & - & - & + & - \\
\hline 31. & L80 & 2.5 & $\mathrm{~F}$ & ND & - & - & + & - \\
\hline 32. & L81 & 3 & $\mathrm{~F}$ & ND & - & - & + & - \\
\hline 33. & L84 & 2 & $\mathrm{~F}$ & Pitbull & - & + & + & - \\
\hline 34. & L85 & 2.5 & $\mathrm{~F}$ & Boxer & - & + & + & - \\
\hline 35. & L87 & 5 & M & Pitbull & - & - & + & - \\
\hline 36. & L89 & 9 & $\mathrm{~F}$ & Spitz & + & - & + & - \\
\hline 37. & L95 & 6 & M & Rottweiler & + & - & + & - \\
\hline 38. & L96 & 3 & $\mathrm{~F}$ & Labrador & + & - & + & - \\
\hline 39. & L97 & 5.5 & $\mathrm{~F}$ & Pitbull & - & + & + & - \\
\hline 40. & L99 & 9 & M & ND & + & - & + & - \\
\hline Total & 40 & & & & & - & + & \\
\hline
\end{tabular}

(-) Negative, (+) Positive, M: Male, F: Female, GSD: German Shepherd Dog, ND: Non-Descript, Pom: Pomeranian 
Thus, the mutations affecting VP2 are mainly responsible for the evolution of different antigenic variants (Mohan Raj et al., 2010). It is mainly responsible for the positive selection resulting in the molecular evolution of CPV (Hoelzer et al., 2008). In a study Decaro et al., (2005) used real-time PCR for the diagnosis of CPV in faecal samples from dogs exhibiting diarrhoea and detected CPV-2 in 73 samples out of a total of 89 samples. Later, Decaro et al., (2006) developed a minor groove binder (MGB) probe based assay to discriminate between type 2based vaccines and field strains of CPV using two MGB probes specific for CPV-2 and the antigenic variants $(2 \mathrm{a}, \quad 2 \mathrm{~b}$ and $2 \mathrm{c})$ respectively. All the antigenic variants $(2 a, 2 b$ and 2c) were labelled with different fluorophores and the MGB probe assay was able to discriminate successfully between the vaccine type and the antigenic variants with good reproducibility. Also, Decaro et al., (2008) characterized a strain of CPV as CPV2c by means of real-time PCR assays using minor groove binding probes in another study.

For the antigenic typing of CPV, we used Real-Time PCR in addition to PCR because of its increased sensitivity and specificity as has been reported by various workers. Shi et al., (2012) reported that the real-time PCR is a sensitive diagnostic tool that may be supplemented to conventional PCR for increased sensitivity in epidemiological and surveillance studies and confirmed that it was highly sensitive, specific and reproducible and could facilitate rapid detection and identification of CPV from different kinds of specimens. Further, Zhao et al., (2013) used Real-time PCR to calculate viral loads in the CPV positive samples thus used Real Time PCR for quantitation.

In India, Kumar and Nandi (2010a) analyzed 47 fecal samples from dogs suspected of CPV- 2 using real time PCR, hem agglutination test and PCR. They observed that 24, 20 and 22 samples were found positive for CPV-2 by real time PCR, HA and PCR respectively indicating that real-time PCR is more sensitive than HA and conventional PCR. Kaur et al., (2016) developed a multiplex real time PCR for antigenic typing of Canine parvovirus from rectal swabs of dogs and the most prevailing antigenic type was found to be CPV-2a.

\section{Sequence analysis}

For the sequence analysis, the PCR products of two samples (one from Madhya Pradesh, M1 and one from Ludhiana, L50) were got sequenced. After obtaining the sequences these were analysed using NCBI BLAST. On the basis of BLAST analysis it was found that the sequences had $99-100 \%$ homology with the Canine Parvovirus.

Thus from the study the incidence of CPV was found to be $18 \%$ and $63 \%$ by PCR and NPCR respectively indicating NPCR to be more sensitive. Further the study also indicated the animals vaccinated for CPV were also found positive for the disease and the most prevailing antigenic type in the samples tested by Real-Time PCR was found to be CPV-2a.

\section{References}

Biswas S, Das P J, Ghosh S K and Pradhan N R. 2006. Detection of canine parvovirus (CPV) DNA by polymerase chain reaction and its prevalence in dogs in and around Kolkata, West Bengal. Indian Journal of Animal Science 76 (4): 324-25.

Carmichael L E and Binn L N. 1981. New enteric viruses in the dogs. Advances in Veterinary Sciences and Comparative Medicine 25: 37.

Decaro N, Elia G, Martella V, Desario C, 
Campolo M, Trani Di, Tarsitano E, Tempesta M and Buonavoglia C. 2005. A realtime PCR assay for rapid detection and quantitation of canine parvovirus type 2 in the feces of dogs. Veterinary Microbiology 105: 19-28.

Decaro N, Desario C, Elia G, Martella V, Mari V, Lavazza A, Nardi $M$ and Buonavoglia C. 2008. Evidence for immunization failure in vaccinated adult dogs infected with canine parvovirus type 2c. New Microbiology 31:125-30.

Decaro N, Elia G, Desario C, Roperto S, Martella V, Campolo M, Lorusso A, Cavalli A and Buonavoglia C. 2006. A minor groove binder probe real time PCR assay for discrimination between type- 2 based vaccines and field strains of canine parvovirus. Journal of Virological Methods 136: 65-70.

Deepa P M and Saseendrannath M R. 2000. Serological studies on canine parvoviral infection. Indian Veterinary Journal 79: 643-44.

Hirasawa T, Kaneshigi T and Mikazuki K. 1994. Sensitive detection of canine parvovirus DNA by the nested polymerase chain reaction. Veterinary Microbiology 41: 135-45.

Hoelzer K, Shackelton L A, Holmes E C and Parrish C R. 2008. Within-host genetic diversity of endemic and emerging parvoviruses of dogs and cats. Journal of Virology 82(22): 11096-105.

Kaur G, Chandra M, Dwivedi P N and Narang D. 2016. Multiplex Real-Time PCR for identification of Canine Parvovirus antigenic types. Journal of Virological Methods 233: 1-5.

Kaur G, Chandra M, Dwivedi P N and Sharma N S. 2015. Prevalence of Canine Parvovirus in dogs in Ludhiana, Punjab. Research in Environment and Life Sciences 8 (2): 157-158.

Kaur G, Chandra M, Kaur H, Ramneek and Dwivedi P N. 2011. Diagnosis of
Canine Parvovirus using Nested-PCR and comparison of blood picture in affected dogs. Indian journal of Canine practice. 3(1): 63-66.

Kumar M and Nandi S. 2010a. Development of a SYBER Green based real-time PCR assay for detection and quantitation of canine parvovirus in faecal samples. Journal of Virological Methods 169(1): 198-201.

Kumar M and Nandi S. 2010b. Molecular typing of canine parvovirus variants by polymerase chain reaction and restriction enzyme analysis. Transboundary and Emerging Disease 57(6): 458-63.

Kumar M, Chidri S and Nandi S. 2011. A sensitive method to detect canine parvoviral DNA in faecal samples by nested polymerase chain reaction. Indian Journal of Biotechnology 10: 183-87.

Mizak B and Rzezutka A. 1999. Application of nested PCR for detection of canine parvovirus in faeces. Bulletin of the Veterinary Institute in Pulawy 43(1): 19-24.

Mochizuki M, Ohshima T, Une Y and Yachi A. 2008. Recombination between vaccine and field strains of Canine Parvovirus is revealed by isolation of virus in canine and feline cell cultures. Journal of Veterinary Medical Science 70(12): 1305-14.

Mochizuki M, San Gabriel M C, Nakatani H and Yoshida M. 1993. Comparison of polymerase chain reaction with virus isolation and haemagglutination assays for the detection of canine parvoviruses in faecal specimens. Research in Veterinary Science 55: 60-63.

MohanRaj J., Mukhopadhyay H. K., Thanislass J., Antony P. X. and Pillai R. M. 2010. Isolation, molecular characterization and phylogenetic analysis of Canine Parvovirus, Infect. 
Genetics Evol., 10(8): 1237-1241.

Parthiban S, Mukhopadhyay H K, Antony P

$X$ and Pillai R M. 2010. Molecular typing of canine parvovirus occurring in Pondicherry by multiplex PCR and PCR-RFLP. Indian Journal of Virology 21(1): 86-89.

Phromnoi S, Sinsiri R and Sirinarumitr T. 2010. Expression of Recombinant VP2 Protein of Canine Parvovirus in Escherichia coli. Kasetsart Journal (Natural Science) 44: 870 -78.

Phukan A, Deka D and Boro P K. 2004.

Occurrence of canine parvovirus infection in and around Guwahati. Indian Journal of Animal Science 74 (4): 930-31.

Ramadass $\mathrm{P}$ and Khader T G A. 1982. Diagnosis of canine parvovirus infection by agar gel precipitation test and fluorescent antibody techniques. Cheiron 11: 323-25.

Sakulwira K, Oraveerkul K and Poovorawan Y. 2001. Detection and genotyping of canine parvovirus in enteric dogs by PCR and RFLP. Science Asia 27: 14347.

Sambrook J and Russell D W. 2001. Molecular cloning: A laboratory Manual. $3^{\text {rd }}$ ed. Cold Spring Harbor Laboratory Press, New York.

Schmitz S, CoenenC, MatthiasK, HeinzJurgen T and NeigerR. 2009. Comparison of three rapid commercial canine parvovirus antigen detection tests with electron microscopy and polymerase chain reaction. Journal of Veterinary Diagnostics Investigation 21: 344-45.
Schunck B, Kraft W and Truyen U. 1995. A simple touchdown polymerase chain reaction for detection of Canine Parvovirus and Feline Panleukopenia virus in faeces. Journal of Virological Methods 55: 427-32.

Shi L, Yin H, Zhao Z, Wang J, Yuan W, Zhu $\mathrm{H}$, Zhang $\mathrm{J}$ and Li G. 2012. Establishment and evaluation of a novel Taqman probe-based real-time PCR for detection of Canine Parvovirus. African Journal of Microbiology Research 6(13): 3134-38.

Singh D, Verma A K, Kumar A, Srivastava M, Singh S K, Tripathi A K, Srivastava $A$ and Ahmed I. 2013. Detection of Canine Parvo Virus by polymerase chain reaction assay and its prevalence in dogs in and around Mathura, UP, India. American Journal of Biochemistry and Molecular Biology ISSN 2150-4210.

Tijssen P, Laekel M, Zadori Z and Hebert B. 1999. Parvoviruses of rodents, pigs, cattle and waterfowl. In: wlebster R G and Grandoff A (eds.) Encyclopedia in virology. $2^{\text {nd }}$ edition. Academic press, San Diego CA.

Weiquan L, Quanshui F, Yu J, Xianzhu X and Wang L. 2001. Establishment of a commonly used PCR technique for detection of carnivore parvoviruses. Chinese Journal of Veterinary Science 21(3): 249-51.

Zhao Y, Lin Y, Zeng X, Lu C and Hou J. 2013. Genotyping and pathobiologic characterization of canine parvovirus circulating in Nanjing, China. Virology Journal 10: 272-372.

\section{How to cite this article:}

Sankalp Singh Kushwaha, Gurpreet Kaur, Mudit Chandra and Dwivedi, P.N. 2018. Identification of the Prevailing Antigenic Types of Canine Parvovirus in Northern and Central India. Int.J.Curr.Microbiol.App.Sci. 7(08): 3881-3889. doi: https://doi.org/10.20546/ijcmas.2018.708.399 